\title{
Dislocated hip in East African infants and children
}

\author{
J. C. GRIFFITHS \\ Ch.M., F.R.C.S. (Ed.) \\ Orthopaedic Surgeon, Royal Manchester Children's Hospital
}

\begin{abstract}
Summary
A true congenital hip dislocation (CDH) occurring in a native African child is described.

Other forms of hip dislocation in Africa are presented.

Differential diagnosis is stressed especially between true CDH and the teratological form.

The rarity of true CDH in Africa is discussed.
\end{abstract}

\section{Introduction}

The purpose of this communication is to describe a patient with a true congenital hip dislocation (CDH), said to be unknown in the African, and to compare this condition with other forms of hip dislocation in African children which may confuse the diagnosis. Although this is not currently a problem of urgent practical importance, the geographical distribution of many obscure disorders is of interest (Burkitt, Nelson \& Williams, 1963), and may lead to the discovery of causative factors. An essential preliminary to any comment on the incidence of true $\mathrm{CDH}$ in the African child is to clarify some diagnostic problems, although at the moment the chances of coming to any sound conclusions about its incidence are remote, since the East African health services are not comprehensive, views are clouded by more important orthopaedic problems, and accurate population statistics are scanty. Nonetheless, patients with well authenticated true congenital hip dislocations should be described and can be usefully contrasted with other forms of neonatal or childhood dislocations.

\section{Materials}

Hip dislocation in neonates is commonly congenital, rarely paralytic. In older children the dislocation may be caused by infection, paralysis or trauma. Under African conditions children can be seen at various ages with long-standing dislocations of the hip and such an incomplete history that it is often difficult to establish a cause. This material is presented in two groups-congenital dislocations and those due to miscellaneous causes.

\section{Group 1-congenital dislocations}

It is generally accepted that congenital dislocation occurs in two groups of patients; the largest group consists of those where there is no genetic defect but where the dislocation is an acquired condition occurring towards the end of pregnancy, related to the temporary occurrence of laxity in the ligaments of the hip and aggravated by adduction and extension of the joint (Wilkinson, 1963). This group can be conveniently termed true CDH. Teratological dislocations form a much smaller group with distinct features; an association with multiple congenital anomalies; difficult and unstable reduction followed by a disappointing response to all forms of treatment; a genetic rather than an acquired aetiology. If there is a varying geographical distribution of congenital hip dislocation it relates almost certainly to true $\mathrm{CDH}$ occurring as a result of some abnormality of intra-uterine environment rather than to the teratological form which might well be widely distributed throughout the world in common with many other genetic defects. Four patients have been seen who fall into the congenital group; each one illustrates a different problem. The first child is a true $\mathrm{CDH}$ and is remarkable as the first known to the author as having occurred in a native African. The second illustrates the difficulty in making a diagnosis in an older child; probably, however, this patient also had had a true CDH even though not seen or radiographed until 13 years of age. The third and fourth patients are teratological dislocations; the former seen in a patient with Seckel's birdheaded dwarfism (McKusick et al., 1967), the latter in association with a multiple epiphyseal dysplasia.

Case 1. A Kikuyu girl was seen at the age of $3 \frac{1}{2}$ years with classical clinical and radiological features of unilateral CDH. She had a marked Trendelenberg limp, adaptive shortening of adductors and apparent shortening of the leg (Fig. 1). Radiographs showed typical features-dislocation, small capital epiphysis and defective acetabulum (Fig. 2). There was no evidence of gluteal paralysis or of any other con- 


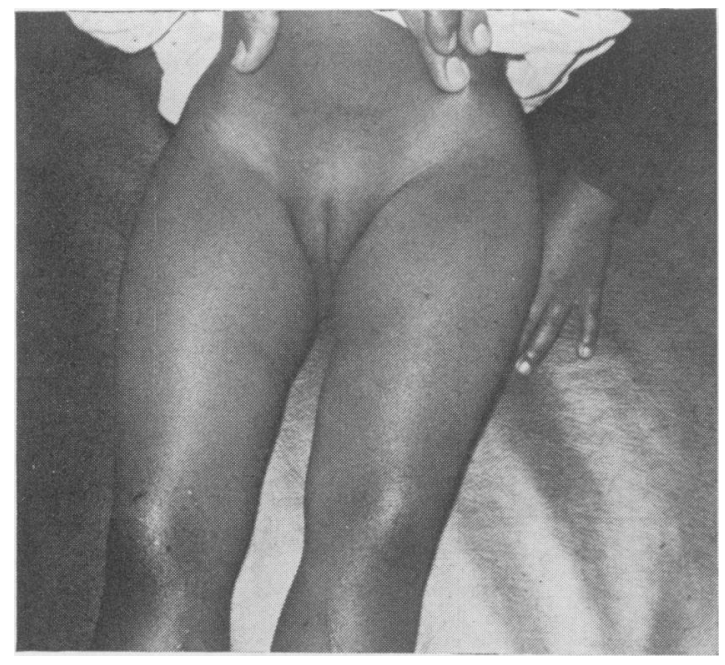

FIG. 1. Case 1. Shortening of the leg.

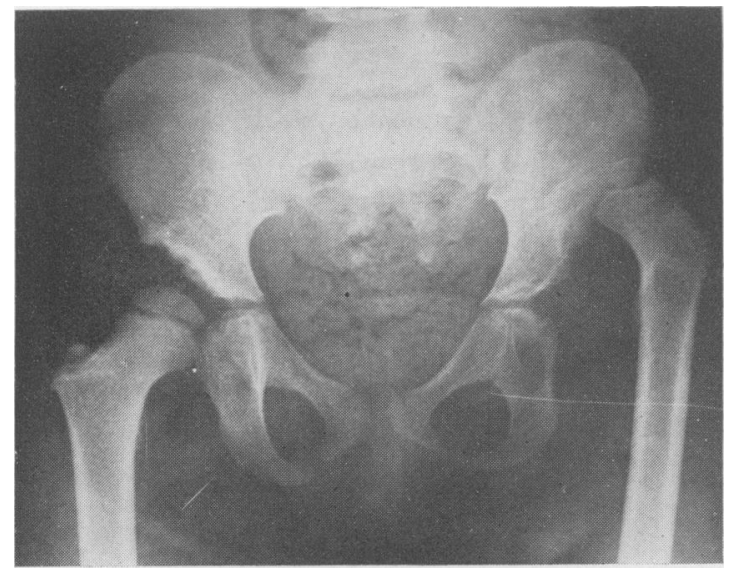

FIG. 2. Case 1. Radiograph showing dislocation, small capital epiphysis and defective acetabulum.

genital anomalies. Open reduction was successful and uncomplicated. Typically the child was female, she was the daughter of educated Kikuyu parents and was never carried on her mother's back with abducted legs (if this is an important prophylactic in Africa-Muller, 1958).

Case 2. This girl was not seen until 13 years of age, complaining of a long-standing limp. Unilateral hip dislocation was seen on X-ray (Fig. 3), compatible with untreated $\mathrm{CDH}$. There was no evidence of poliomyelitis. As in the first patient, this girl's Kikuyu parents were westernized.

Case 3. This child was seen when 2 years old. She was unable to walk or stand erect. A striking

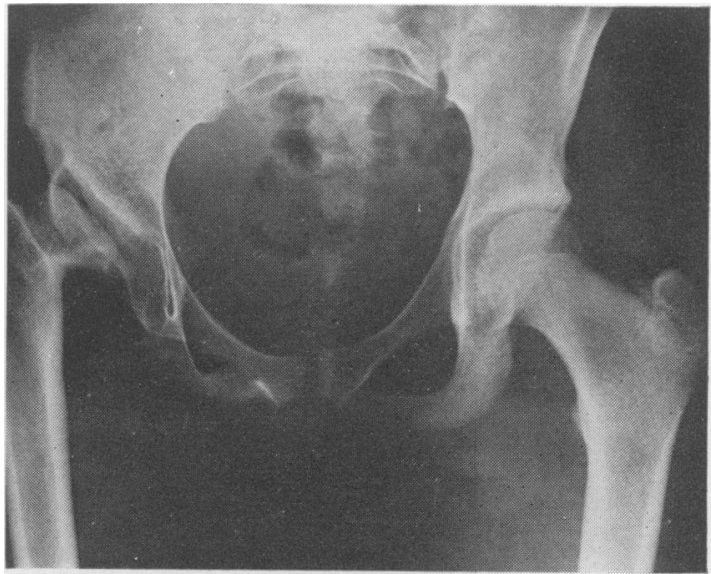

Fig. 3. Case 2. Unilateral dislocation of the hip.

degree of microcephaly was seen and although the child seemed of cheerful disposition intelligence was obviously low. Radiographs showed bilateral hip dislocation. After adductor tenotomy the hips were manipulated and a frog plaster applied. Six months later Batchelor plasters were applied, the hips seeming to remain reduced. After a further 6 months bilateral de-rotation osteotomies were done. Radiographs after completion of treatment (Fig. 4) show a poor result especially on one side. The clinical result was even worse, as the child was still unable to walk several months later and began to develop signs of stiffness and contracture in the knees. Many of the clinical features here are in accordance with a diagnosis of Seckel's bird-headed dwarfism (McKusick et al., 1968). These authors describe several patients, one of whom had bilateral hip dislocation and was unable to walk.

Case 4. This male child of 6 years exhibited gross deformities of hips and knees (Fig. 5). Radiographs showed dislocation of both hips with abnormal epiphyses at both ends of the femora (Fig. 6). The child was mentally retarded, unable to speak and had poor hearing.

\section{Group 2-miscellaneous causes of hip dislocation in children}

Brief notes are given here to illustrate some patients with dislocations in early childhood which were not congenital but could, in the absence of an adequate history, be misinterpreted.

Paralytic dislocations. It is possible for neonatal paralytic dislocation to occur but only in myelomeningocoele of such severe proportions that intrauterine paralysis has been established for some time. Such children seldom survive in Africa and, consequently, rarely demand orthopaedic care. Paralytic 
Fig. 4. Case 3. Radiograph after completion of treatment, showing poor result on one side.
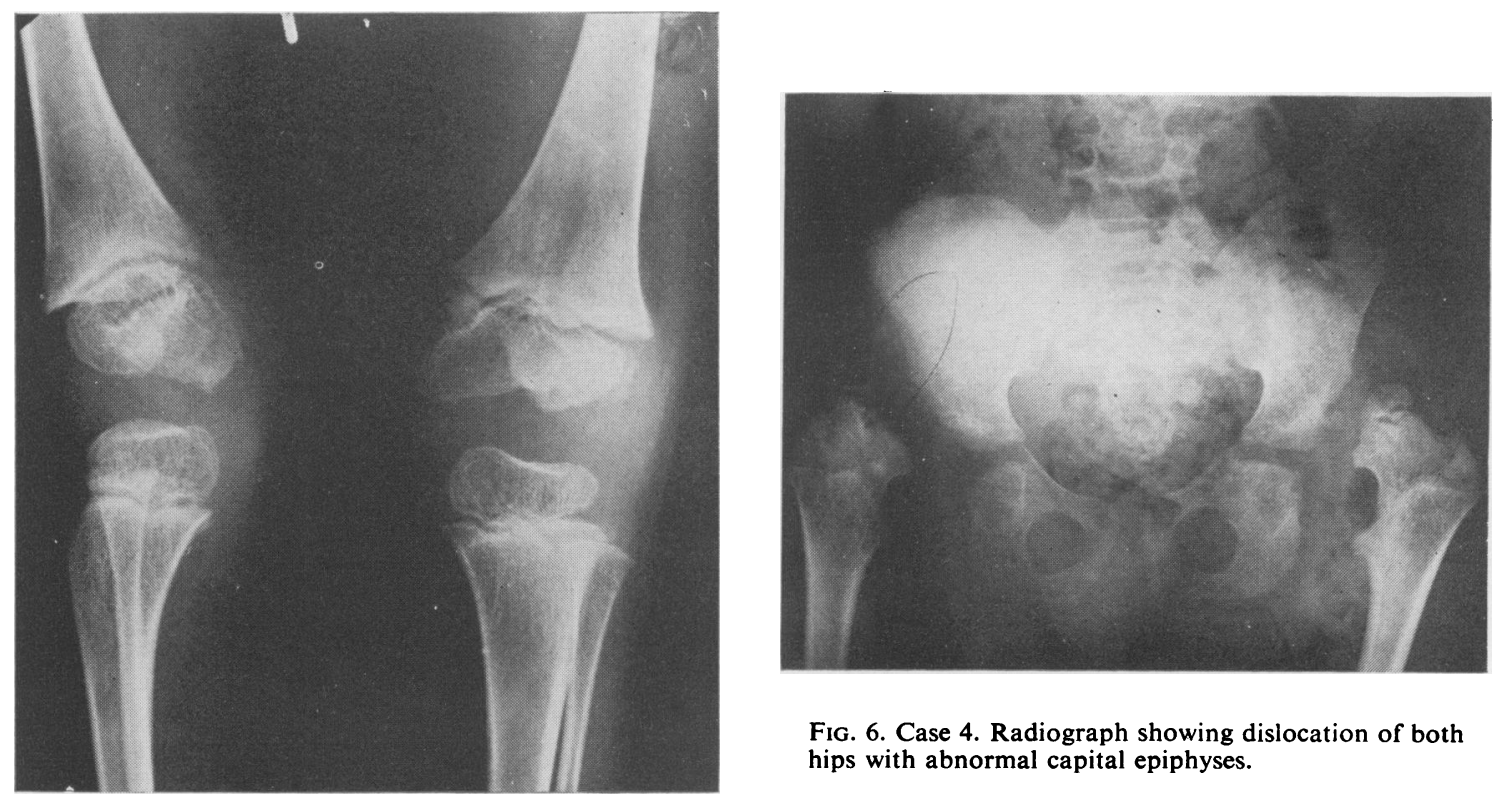

Fig. 6. Case 4. Radiograph showing dislocation of both hips with abnormal capital epiphyses.

FIG. 5. Case 4. Epiphyseal abnormalities of knees. 
dislocations appear in older children when the glutei have been affected by poliomyelitis. Clinical features are of a unilateral dislocation with evidence of paralysis elsewhere. Radiological signs are less important. Acetabular development will depend on the age at which dislocation has occurred. Even in a young child dysplasia will be quite mild since the femoral head has lain within the acetabulum during the critical early days of its development (Fig. 7). In other cases the acetabulum may show signs of

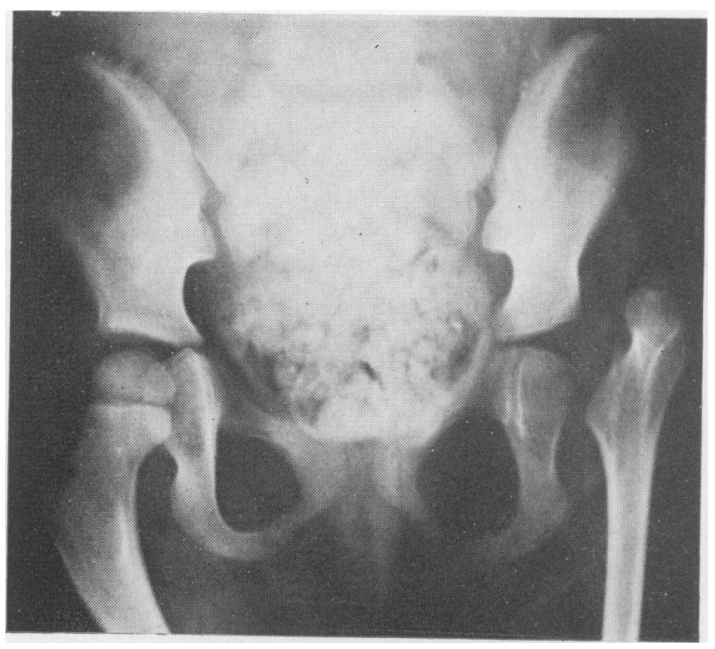

FIG. 7. Paralytic dislocation in a young child, showing mild acetabular dysplasia. obliquity even when the hip is not yet completely dislocated (Fig. 8); this is perhaps due to erosion of the acetabular margin by an unstable femoral head (Sharrard, 1964). A most distinctive feature is valgus of the femoral neck which is sometimes quite gross (Fig. 7).

Infective dislocations. Gross joint destruction is a well-known feature of pyogenic arthritis. The appearances are usually characteristic. A dislocation does not always occur, however, but rather a complete displacement of the capital epiphysis on the femoral neck (Fig. 9). The dislocation can be complete after smallpox arthropathy, and is frequently symmetrical (Fig. 10). The late results of infantile septic arthritis are especially prone to confuse, and in the bilateral form can be mistaken for $\mathrm{CDH}$. This problem can be illustrated by the following patient.

Case 5. A Kikuyu boy was first seen when 2 years old and was thought to have a bilateral CDH. Manipulative reduction was attempted and Batchelor's plasters applied. This proved unsatisfactory and was followed by an open reduction of each hip in turn, and an attempted creation of an acstabular roof. After 1 year the patient was ambulant but had a severe flexion-adduction contracture of each hip; 1 year later still, when first seen by the author, further radiographs showed both hips still dislocated and, of great significance, a complete absence of both femoral capital epiphyses. Careful elucidation of the history revealed that, when one month old, the child had had an osteomyelitis of the leg followed by

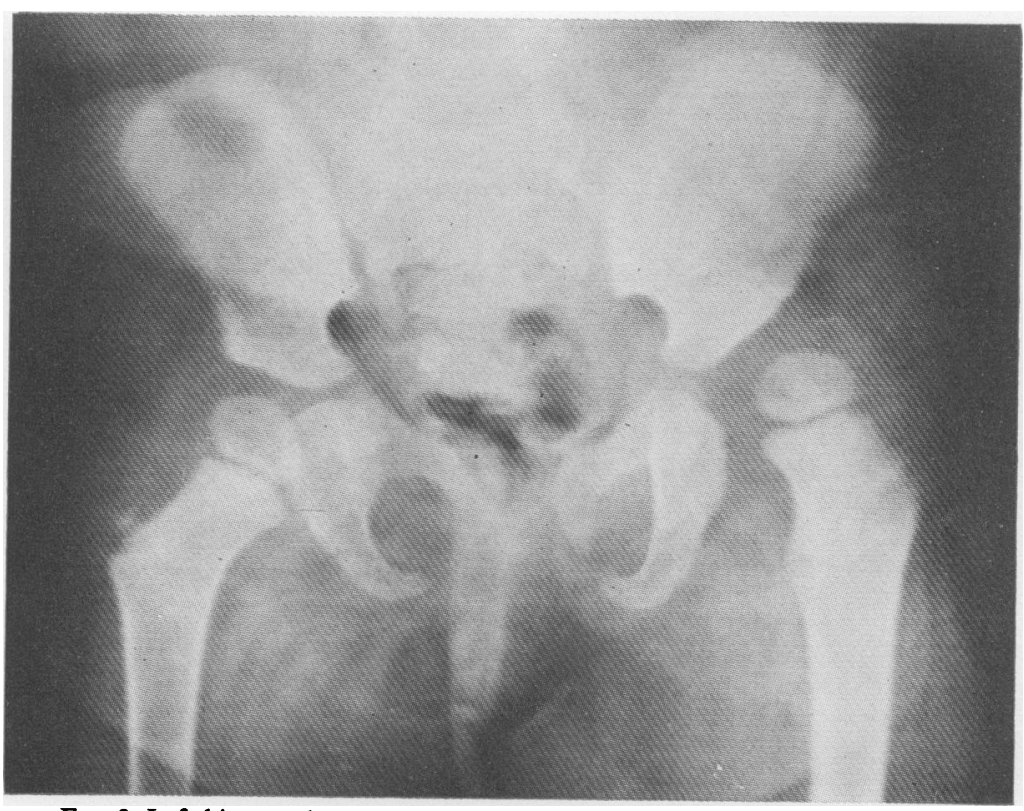

FIG. 8. Left hip poorly contained. The acetabulum shows signs of obliquity. 


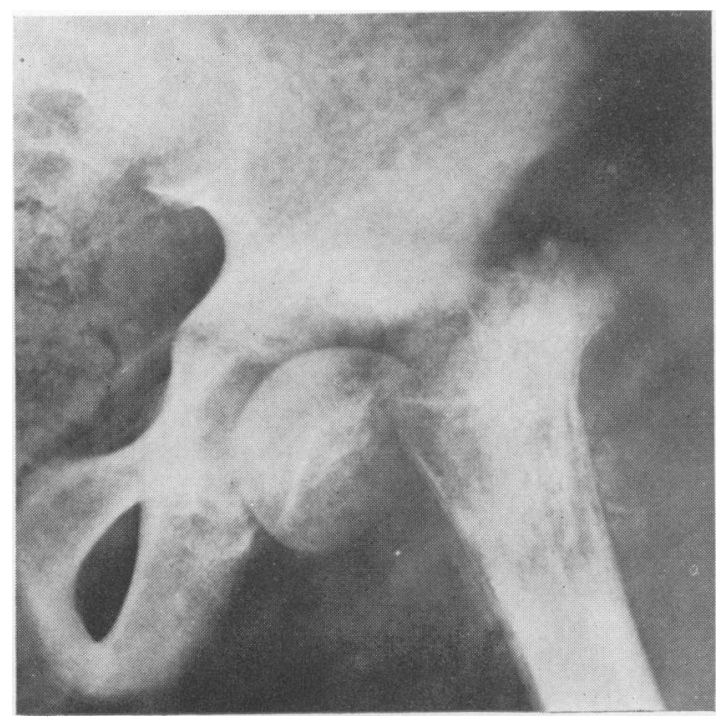

FIG. 9. Infective dislocation. Complete trans-epiphyseal displacement of femoral head.

recurrent abscesses. It is clear that he must also have had a bilateral infantile septic arthritis. A useful pointer to the correct diagnosis, apart from the history, is a persistent absence of femoral capital epiphyses.

\section{Discussion}

The foregoing patients demonstrate clearly the multiplicity of causes of hip dislocation in native
African children. Huckstep's statement (1966) that care must be taken when making a diagnosis of true $\mathrm{CDH}$ is supported since other causes can produce superficially similar appearances. Differentiation of paralytic dislocations, dislocation as a late sequel of neonatal septic arthritis and traumatic dislocation is usually simple. It is likely, however, that a relatively superficial inspection of the problem will confuse a teratological dislocation with a true $\mathrm{CDH}$. It is my contention that teratological dislocation is just as common in Africa as elsewhere, whereas a true $\mathrm{CDH}$ is very rare even though it can occur (as shown by Case 1 in this small series). Teratological dislocation has been recognized for many years, initially by Le Damany (1908). It can be suspected when reduction is difficult and unstable and confirmed when clearly associated with other congenital anomalies. Teratological hip dislocations have been seen by the author in association with ipsilateral club foot, Spregel's shoulder, and Pierre-Robin Syndrome. It has also been described in a patient with Albright's hereditary osteodystrophy (Kelly, 1968). Such dislocations are, of course, rare in Europe and America by comparison with true CDH. Palmen (1961) found an incidence of only $1.8 \%$ in a large series of hip dislocations in Sweden. Barlow (personal communication 1968) has only seen it once in 27,622 neonates examined at birth.

The apparent rarity of true $\mathrm{CDH}$ in Africa remains unexplained. It has been attributed partly to pre-natal and partly to post-natal environmental influences. Pre-natal influences were thought to determine the negative results on Ortolani testing of

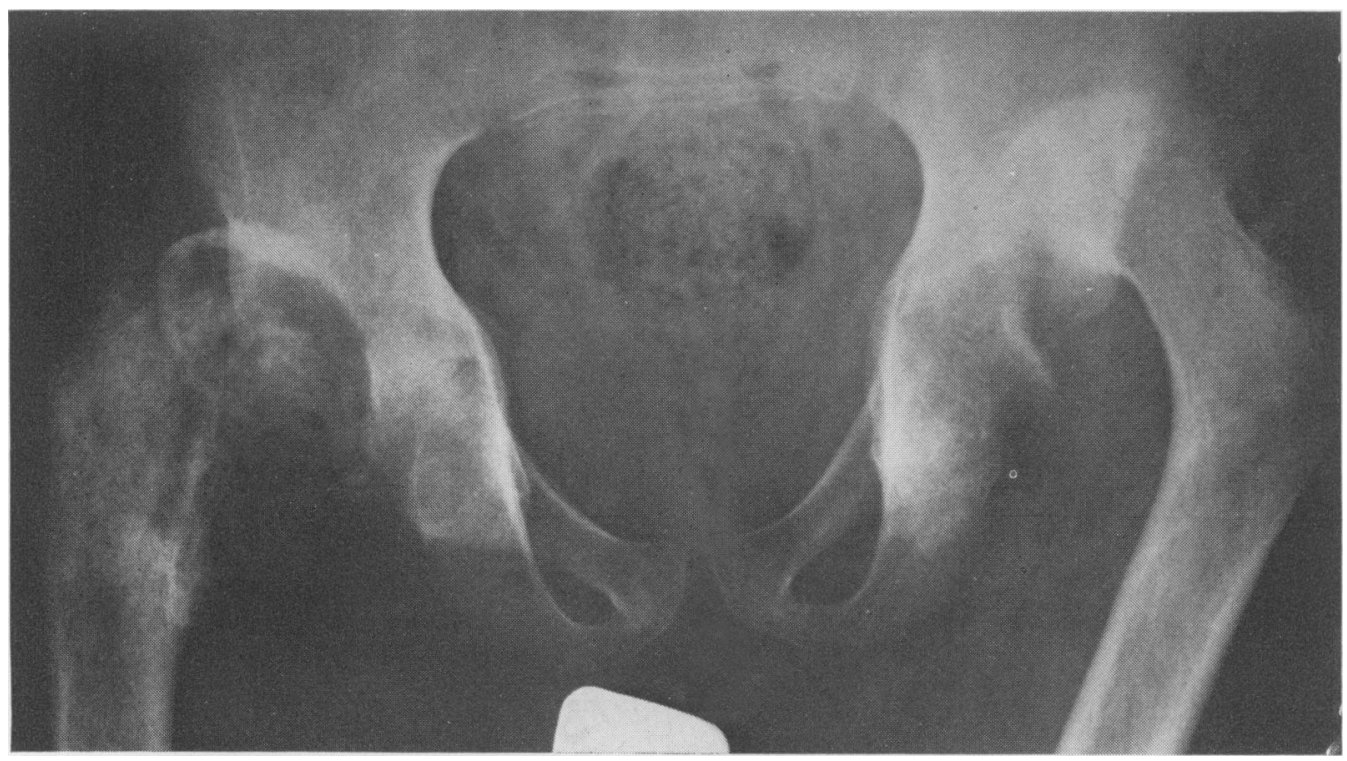

Fig. 10. Infective dislocation after smallpox arthropathy. 
several thousand Bantu neonates in Johannesburg (Edelstein, 1966). Post-natal influences as determined by extension and adduction of the hips on a cradleboard contributed to a high frequency of CDH in North American Indians (Salter, 1966). Thus it has been assumed (Muller, 1958) that the opposite posture of the hips traditionally seen in the carriage of the African child is of major importance in preventing the development of true $\mathrm{CDH}$. Huckstep (1966) has pointed out, however, that increasing westernization in Uganda has not so far been associated with a rising incidence of $\mathrm{CDH}$. Indeed, if the situation is examined critically, carriage of the baby across the back, abdomen or hip does not commence until the child is 4 weeks old or more-rather late to be an effective form of treatment. The practice, moreover, is not universal among African tribes, being mainly applicable to those agrarian peoples whose womenfolk carry their babies thus while at work in the fields. The most that can be claimed is that the more primitive African families allow their babies full freedom of movement so that their hips will tend to lie in abduction and flexion rather than the reverse for most of the time (Salter, 1968).

To reach any valid conclusion more information is needed. At the moment it seems that the pre-natal environment is the variable which determines the rarity of true $\mathrm{CDH}$ in native Africans. One must not assume, however, a uniform situation for the whole of Africa since it is quite likely that the incidence of true $\mathrm{CDH}$ may vary within the continent. If this could be shown to be so, information of aetiological value might be obtained.

\section{References}

Burkitt, D.P., Nelson, C.L. \& Williams, C.H. (1963) Some geographical variations in disease patterns in East and Central Africa. East African Medical Journal, 40, 1.

Edelstein, J. (1966) Congenital dislocation of hip in the Bantu. Journal of Bone and Joint Surgery, 45B, 397.

HUCKSTEP, R. (1966) Orthopaedic problems in East Africa. Journal of the Royal College of Surgeons of Edinburgh, 11, 206.

KELLY, J.J. (1968) Albright's hereditary osteodystrophy associated with bilateral hip dislocation. British Journal of Clinical Practice, 22, 399.

Le Damany, P. (1908) Die angeborene Huftgelenksverenkurg. Zeitschrift für orthopädische Chirurgie, 21, 129.

McKusick, V.A., Mahloudj, M., Авbott, M.H., LindenBERG, R. \& KEPAS, D. (1967) Seckel's bird-headed dwarfism. New England Journal of Medicine, 277, 279.

Muller, G.M. (1958) Diseases of Childhood in Tropics and Subtropics (Ed. by H. C. Trowell and D. B. Jelliffe), p.527. Edward Arnold, London.

Palmen, K. (1961) Preluxation of the hip joint. Acta paediatrica Scandinavica, 50, Suppl.129, 58.

SAlter, R.B. (1966) Role of innominate osteotomy in the treatment of congenital dislocation and subluxation of the hip in the older child. Journal of Bone and Joint Surgery, 48A, 1413.

SAlTER, R.B. (1968) Aetiology, pathogenesis and possible presentation of congenital dislocation of the hip. Canadian Medical Association Journal, 98/20, 933.

Sharrard, W.J.W. (1964) Posterior iliopsoas transplantation in treatment of paralytic hip dislocation. Journal of Bone and Joint Surgery, 46B, 426.

Wilkinson, J.A. (1963) Prime factors in the aetiology of congenital dislocation of the hip. Journal of Bone and Joint Surgery, 45B, 268. 